\title{
Publish and be Damned a Second Time
}

Now that Mr Herman Kahn has made it respectable to think the unthinkable, it may be appropriate to ask what virtues still attach to the convention that reports of original scientific research should not be published more than once. Most scientific journals, Nature included, take a stern view of breaches of this convention and most scientists seem first of all to approve of the convention and then to do their best to live by it. The arguments for a rigid rule against multiple publication are of course familiar. The literature is full enough already, and if multiple publication became common practice, the speed with which libraries are forced to throw up their hands in despair would be enormously increased. But multiple publication can also cause bibliographical chaos. The problems of knowing whether two apparently similar titles by the same authors refer to substantially the same original article would turn every working scientist into a textual analyst. At the same time, it is only fair to recognize that there have grown up practices which consist of variations of the strict convention that those who publish the same article twice are guilty of dishonourable conduct. By now, for example, preliminary communications are widely recognized to be useful ways of making public important discoveries, but there are good reasons for complaint if the fuller version of the discoverer's report does not eventually materialize. More reprehensible, there has been a tendency in the past few years for reports of original research, once published, to pop up again in closely related forms as contributions to symposia, international conferences and other occasions on which professional scientists have been persuaded to travel. The equation between the seminar paper and the airline ticket is now uncomfortably precise.

In all these circumstances, it would of course be overzealous of a journal such as Nature to follow too rigid a policy, but there are some circumstances in which multiple publication is not merely an offence against accepted conventions but an assault on ordinary standards of decent behaviour. Earlier this year, there appeared in: Nature Physical Science an article of some importance which was described by the principal author as "an extremely important breakthrough into the new field of ...". With all despatch, the article was sent to a referee and published in the usual way. Only afterwards did it become known that the same article had been submitted to two other journals. By all accounts, it seems that the article was rejected by one journal but published, in a format substantially the same as that which appeared in Nature, by the second. Since then, the hapless authors have been assailed by several editors and the senior author has actually written to say "We were all very excited at the time and I would like you to think that my apparent breakdown in publication ethics was the result of overenthusiasm." With some regret, it has been decided not to publish the names of those concerned in this shabby business, but to scrutinize with immense care their claims to originality for other publications. In the long run, however, a public register of such offenders may turn out to be the best method of keeping authors on a straight and narrow path. No doubt such a record would have some of the attractions of a gossip column as well.
Another issue involving a form of alternative publication is much harder to resolve. In the past two decades, newspapers have become increasingly enterprising sources of scientific news. In the long run, of course, this is of public benefit, but there have been times when the editors of journals have been embarrassed to discover that the essence of some cherished article has been given to the daily press in such detail that full publication seems a mere formality. Thus there has grown up a running battle between some journals, with Physical Review Letters at their head, and those newspapers and magazines which have such a flair for seizing on important discoveries that they are, almost by definition, the best newspapers. It is only fair to say that the distinction between proper and improper practices is extremely hard to make in this connexion. Certainly there can be no rigid rule. It is also unreasonable to expect that the authors of an important discovery should keep this strictly to themselves for months on end while waiting for the solemn processes of formal publication to be completed. Not merely is this unnecessary but impractical as well, now that journalists habitually turn up at scientific meetings. And it would, of course, be altogether too toffce-nosed to ask that news of scientific discoveries should be kept even from the audiences at scientific meetings until the mills of the publication process have begun to grind. So it seems to follow that journals, Nature included, can ask authors to refrain from telling newspapers their good news only if the process of publication is reasonably swift. What matters is that the relationship between an author and the editors of the journal in which he seeks to publish should be open and courteous. And even then, there are bound to be occasions when news leaks out. In short, although journals are right to ask that their contributors will not call a press conference whenever a manuscript is accepted for publication, their best insurance against being scooped by the newspapers is to publish quickly.

\section{Years Ago}

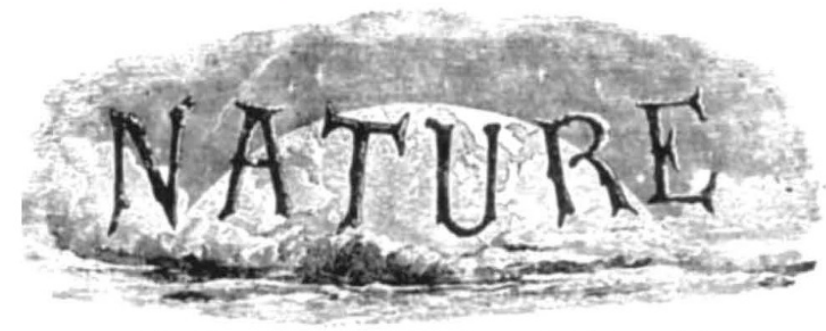

The First Commissioner of Works and Public Buildings announces that he intends again to distribute this autumn, among the working classes and the poor inhabitants of London, the surplus bedding-out plants in Battersea, Hyde, the Regent's, and Victoria Parks, and in the Royal Gardens, Kew. If the clergy, school committees, and others interested, will make application to the superintendents of the parks nearest to their respective parishes, or to the director of the Royal Gardens, Kew, in the cases of persons residing in that neighbou,hood, they will receive early intimation of the number of plants that can be allotted to each applicant, and of the time and manner of their distribution.

From Nature, 4, 453, October 5, 1871 